\title{
O PODER CONCLUSIVO DAS COMISSÕES DA CÂMARA DOS DEPUTADOS NA 52ª LEGISLATURA*
}

\section{Carla Danice de Melo Santos**}

Resumo: Estudo do sistema de comissões e seu poder de apreciação conclusiva: origem histórica e aplicação na Câmara dos Deputados. Pesquisa de dados sobre a tramitação dos projetos de lei sujeitos à competência plena das comissões apresentados na $52^{\mathrm{a}}$ Legislatura. Análise comparativa dos dados em relação a estudos anteriormente realizados.

Palavras-chave: poder conclusivo; sistema de comissões; Câmara dos Deputados; processo legislativo; projeto de lei; legislatura.

Resumen: Estudios del sistema de comisiones y su competencia legislativa plena: origen histórica y aplicación en la Cámara de los Diputados. Investigación de datos sobre la tramitación de los proyectos de ley sujetos a la competencia plena de las comisiones presentados en la $52^{\mathrm{a}}$ Legislatura. Análisis comparativa de los datos en relación a estudios realizados.

Palabras-clave: competencia legislativa plena; sistema de comisiones; Cámara de los Diputados; proceso legislativo; proyecto de ley; legislatura.

\section{Introdução}

Com a intenção de criar procedimentos capazes de agilizar o processo legislativo e de valorizar os órgãos técnicos, o Constituinte de 1988 conferiu às comissões parlamentares, por meio do art. 58, $\S 2^{\circ}$, da Carta Magna, poderes para substituir o Plenário na deliberação de projetos de lei, tendo deixado aos regimentos internos de cada Casa legislativa a atribuição de definir e delimitar os contornos desse novo mecanismo.

\footnotetext{
Artigo produzido a partir de monografia apresentada à Câmara dos Deputados, como trabalho final do Curso de Especialização em Processo Legislativo, sob orientação da Prof ${ }^{a}$ Luciana Botelho Pacheco .

** Técnica Legislativa da Câmara dos Deputados. Especialista em Processo Legislativo pelo Programa de PósGraduação do Centro de Formação, Treinamento e Aperfeiçoamento da Câmara dos Deputados carla.santos@camara.gov.br
} 
Não obstante essa intenção constitucional de fortalecer as comissões e dotá-las de maior poder decisório, boa parte das pesquisas realizadas por cientistas políticos dedicados ao estudo do Legislativo brasileiro indica que esse objetivo não foi alcançado. Conforme Cintra e Lacombe (2004, p. 161-162), as conclusões, no geral, são de que as comissões, por variados motivos, utilizam bem pouco o poder que lhes foi outorgado, o que resulta em um círculo vicioso de enfraquecimento e esvaziamento desses órgãos técnicos.

A maioria das publicações existentes, contudo, baseia-se em dados coletados nas primeiras legislaturas que se seguiram à nova ordem constitucional, ou seja, quando esse mecanismo do poder conclusivo das comissões ainda estava se incorporando e adaptando à prática e às normas internas da Casa. Mais recentemente, a publicação de um "Anuário Estatístico" referente aos trabalhos legislativos da Câmara dos Deputados no ano de 2005 revelou dados um pouco diferentes, o que nos fez cogitar da possibilidade de aquele panorama desfavorável sobre o poder conclusivo traçado pelos primeiros estudiosos ter sofrido alterações, passadas mais três legislaturas desde então.

$\mathrm{O}$ que se pretende investigar neste artigo, a partir desse cenário de disparidades entre dados coletados nas primeiras legislaturas e aqueles referentes a um ano da legislatura mais recente, é se as modificações mostradas pelo anuário estatístico de 2005 em relação às pesquisas anteriormente divulgadas seriam um fenômeno isolado, limitado àquele ano, ou se, ao contrário, efetivamente houve evolução e amadurecimento institucional do mecanismo do poder decisório das comissões desde a sua instituição pela Constituição Federal de 1988 até hoje. Para atingir esse objetivo, propusemo-nos a pesquisar qual foi, efetivamente, a contribuição do poder conclusivo nos trabalhos legislativos efetuados pela Câmara dos Deputados durante todo o período da última legislatura, que se encerrou em 31 de janeiro de 2007.

Este artigo divide-se em duas partes. Na primeira delas abordamos alguns pontos sobre o poder conclusivo das comissões parlamentares, sua previsão na Constituição brasileira de 1988 e a inclusão e as características do instituto dentro do sistema de comissões da Câmara dos Deputados. A segunda parte do trabalho contempla os dados apurados sobre a produção do poder conclusivo das comissões da Casa na última legislatura, trazendo as informações mais atualizadas sobre seu desempenho no conjunto dos trabalhos legislativos. Por fim, apresentamos nossa análise dos resultados encontrados e as conclusões do trabalho.

\section{O sistema de comissões parlamentares e seu poder de apreciação conclusiva}

O sistema de comissões parlamentares, formado pela criação, na estrutura dos Legislativos, de organizações compostas por pequeno número de parlamentares e dotadas de competências pré-estabelecidas, é co-partícipe do processo legislativo. São as comissões as responsáveis por estudar as proposições e redigir as leis, entretanto somente o exame prévio das 
proposições legislativas pelas comissões não foi suficiente para fazer a produtividade legislativa corresponder às demandas cada vez maiores, e de caráter cada vez mais técnico, da era do Estado Social.

Em busca de métodos que possibilitassem produzir mais agilmente a legislação demandada, a Assembléia Constituinte Italiana de 1946 adotou um novo mecanismo de elaboração legislativa, chamado por Mortati (apud SEGADO, 2003, p. 280) de "procedimiento descentralizado", que consistia em atribuir às comissões parlamentares a competência para não somente examinar, mas, também, deliberar, em decisão final, sobre proposições legislativas sem o pronunciamento do Plenário. A finalidade de sua criação era clara: desincumbir os plenários de apreciar um grande número de projetos de lei. Com isso, as comissões, de simples órgãos auxiliares no trabalho legislativo, transformaram-se em órgãos com poder de decisão legislativa.

No Brasil, seguindo o mesmo caminho tomado pela Constituição Italiana, a Assembléia Nacional Constituinte de 1986-87 instituiu, no texto constitucional de 1988, a competência deliberativa plena das comissões parlamentares. O texto constitucional discrimina, no $\S 2^{\circ}$ do artigo 58, as atribuições das comissões, e, dentre elas, a de discutir e votar projetos de lei que, segundo o Regimento Interno da Câmara dos Deputados (RICD), dispensem a deliberação do plenário, sempre resguardada essa apreciação se assim o requererem um décimo dos parlamentares da Casa.

Na elaboração de seu Regimento Interno de 1989, a Câmara dos Deputados estabeleceu, no art. 24, II, a competência conclusiva das comissões como a regra geral de apreciação, ao determinar, especificamente, os casos em que ela não seria aplicada. Assim, foram dotadas as comissões de um poder bastante amplo, pelo menos em termos numéricos, uma vez que, não se encaixando em nenhuma das exceções, a grande maioria dos projetos de lei acabaram por se sujeitar a tal tipo de apreciação.

Várias são, todavia, as causas determinadas pelo RICD que podem levar as proposições a tornarem-se sujeitas à apreciação pelo Plenário, perdendo, assim, as comissões competentes o poder de sobre elas deliberarem.

Em primeiro lugar, há o recurso previsto constitucionalmente contra o resultado da deliberação definitiva das comissões, seja pela aprovação, seja pela rejeição. A segunda hipótese diz respeito à existência de pareceres divergentes entre as comissões competentes para se pronunciarem sobre a proposição. Essa regra assegura que somente sejam decididas conclusivamente pelas comissões as proposições que nelas sejam consensuais. Uma terceira disposição regimental determina que projetos de lei em regime de urgência não podem ser deliberados conclusivamente pelas comissões.

Há mais duas hipóteses que igualmente levam à reversão do rito de apreciação da matéria, remetendo-a para o Plenário. Uma delas consiste na apensação de proposição originalmente sujeita ao rito conclusivo a uma outra, dependente de decisão do Plenário. Assim, 
o rito especial - no caso, o de Plenário - sobrepõe-se ao rito comum, passando ambas as proposições a tramitar segundo o primeiro. A outra ocorre quando, não cumpridos os prazos de apreciação pela comissão, o Presidente da Câmara determine a avocação da proposição para a deliberação em Plenário.

Existe ainda um outro tipo de competência que, além da conclusiva, é também realizada no âmbito das comissões e que pode pôr fim à tramitação de qualquer proposição legislativa. Tal prerrogativa é denominada de apreciação terminativa e aplica-se a todas as matérias a serem deliberadas pela Casa, inclusive as que estejam sujeitas à apreciação conclusiva. Além disso, ela é decisória e privativa de apenas duas comissões: a Comissão de Constituição e Justiça e de Cidadania, quanto aos aspectos de admissibilidade jurídica; e a Comissão de Finanças e Tributação, quanto aos aspectos de admissibilidade financeiro-orçamentária.

\section{Apresentação da pesquisa e análise dos dados}

A pesquisa foi realizada por meio do Sistema de Informações Legislativas da Câmara dos Deputados (SILEG) e teve por base os projetos de lei apresentados durante a $52^{\mathrm{a}}$ Legislatura, isto é, no período de 15/02/2003 a 31/01/2007. O fato de o período escolhido envolver uma legislatura inteira permitiu que este trabalho disponibilizasse resultados bastante recentes, viabilizando, assim, um bom comparativo com trabalhos anteriores, de forma a demonstrar o desenvolvimento histórico do procedimento legislativo descentralizado na Câmara dos Deputados.

O universo pesquisado consistiu nas proposições sujeitas à apreciação conclusiva pelas comissões que permaneciam em tramitação ao final da legislatura, além dos projetos de lei transformados em norma jurídica, tanto pelo procedimento descentralizado, quanto por deliberação plenária. Abordaram-se, também, os projetos que foram arquivados em decorrência do poder de rejeição definitiva das comissões.

A tabulação dos dados foi feita por parâmetros de quantidade de aprovação e rejeição pelas comissões, de forma de apreciação e regime de tramitação das normas jurídicas produzidas e de autoria. Buscou-se, assim, demonstrar os resultados efetivos do trabalho legislativo realizado pelas comissões no uso do poder conclusivo.

\subsection{Dados apurados}

Do total de 7.709 projetos de lei apresentados à Câmara dos Deputados, entre 15/2/2003 e 31/1/2007, 5.529 ainda se sujeitavam à apreciação conclusiva das comissões no final do citado período. Dentre esses, apenas 592 (10,7\%) permaneciam ativos, isto é, continuavam tramitando e os restantes 4.937 (89,3\%) estavam inativos ao final da legislatura. O número de projetos de lei inativos consistia em 4.686 arquivados (94,92\%) e em 251 (5,08\%) que cessaram sua 
tramitação por outros motivos, como, por exemplo, os retirados pelos autores e os que foram a eles devolvidos pela Presidência, conforme o art. $137, \S^{\circ}$ do RICD.

$\mathrm{O}$ arquivamento pode ser determinado por vários fatores definidos pelo RICD. Dentre eles, a chegada do fim da legislatura sem ter a proposição logrado deliberação favorável nas comissões ou encaixar-se ela em alguma das exceções previstas no art. 105. O arquivamento também pode ocorrer na hipótese de declaração de prejudicialidade (art. 163) ou em caso de emissão de parecer terminativo pelas Comissões de Constituição e Justiça e de Cidadania ou de Finanças e Tributação (art. 54). Destaca-se, por último, o tipo de arquivamento resultante da rejeição de mérito das proposições pelas comissões, quando tal decisão não é alvo de recurso ao Plenário (art. 133).

Identificamos, no universo pesquisado, 3.814 projetos arquivados $(81,39 \%)$ em razão do encerramento da legislatura; 204 (4,35\%) declarados prejudicados; 104 (2,22\%) que receberam parecer terminativo quanto aos aspectos de admissibilidade jurídica ou orçamentária; e $564(12,04 \%)$ rejeitados no mérito pelas comissões.

Quanto aos 592 projetos que permaneciam em tramitação, a pesquisa constatou que 452 deles $(76,35 \%)$ encontravam-se em alguma das situações previstas no art. 105 do RICD que impedem o arquivamento ao final da legislatura, quais sejam: 1) ter recebido pareceres favoráveis de todas as comissões; 2) ser de iniciativa externa à Casa; ou 3) já ter tramitado pelo Senado Federal. As 140 proposições restantes $(23,65 \%)$ já haviam terminado sua tramitação pelas comissões, das quais 120 foram remetidas ao Senado Federal para revisão, nos termos da Constituição Federal, e 20 sofreram interposição de recursos para apreciação pelo Plenário, recursos esses que ainda se encontravam pendentes de deliberação.

Além das proposições definitivamente eliminadas do processo legislativo por inadmissibilidade quanto aos aspectos jurídicos ou orçamentários (104 sujeitas à apreciação conclusiva das comissões e 12 sujeitas à deliberação do Plenário) ou por rejeição quanto ao mérito (564) e das que, aprovadas, aguardavam retorno do Senado Federal (120), o poder conclusivo na Câmara dos Deputados produziu 69 leis, isto é, proposições que, aprovadas pelas comissões da Casa e pelo Senado Federal, foram sancionadas pelo Presidente da República.

De posse desses dados, buscou-se comparar a aprovação de projetos de lei via poder conclusivo das comissões, em termos quantitativos, à do processo tradicional, em deliberação do Plenário. Foram revelados os seguintes números referentes tanto às proposições que se transformaram em norma jurídica, quanto às que foram remetidas ao Senado Federal (tabela 1): 
Tabela 1 . Projetos de lei apreciados pelas comissões e pelo Plenário

\begin{tabular}{c|c|c|c}
\hline Situação & Comissões & Plenário & Totais \\
\hline Transformados em normas jurídicas & 69 & 91 & 160 \\
Remetidos ao SF & 120 & 6 & 126 \\
\hline Totais & 189 & 97 & 286 \\
\hline
\end{tabular}

Fonte: Câmara dos Deputados - SILEG

É interessante notar que, em relação ao número total, as proposições aprovadas pelas comissões (189) superaram em cerca de 95\% as aprovadas pelo Plenário (97). No entanto, quando se consideram apenas os projetos transformados em lei, isto é, aqueles já aprovados também pelo Senado Federal e sancionados pelo Presidente da República, a pesquisa demonstra que o Plenário produziu mais que as comissões. Apesar disso, as comissões foram responsáveis por mais de $43 \%$ da produção legal da legislatura passada (69 do total de 160 leis).

Um outro aspecto a ser destacado é a iniciativa dessas leis. Em relação às 69 apreciadas pelas comissões, a Câmara dos Deputados foi autora em 34 casos $(49,27 \%)$, o que superou em quase $80 \%$ a autoria do Poder Executivo, que se deu em 19 leis (27,54\%). O Senado Federal foi autor de 13 leis $(18,84 \%)$ e as 3 restantes $(4,35 \%)$ foram de iniciativa do Tribunal Superior do Trabalho. Quanto às 91 leis apreciadas pelo Plenário, entretanto, a pesquisa evidenciou que a grande maioria dos projetos foi de iniciativa do Poder Executivo, autor em 53 casos $(58,24 \%)$, enquanto apenas $15(16,48 \%)$ tiveram iniciativa da Câmara dos Deputados (13 de Deputados e 2 da Mesa Diretora), 10 (11\%) do Senado Federal, 2 (2,2\%) de comissões mistas especiais e 11 $(12,08 \%)$ de outros órgãos.

No que diz respeito ao regime de tramitação, observou-se que, dos 91 projetos de lei apreciados pelo Plenário e transformados em norma jurídica, apenas $3(3,3 \%)$ tramitaram em regime ordinário ou de prioridade e 88 (96,7\%) estavam sob o regime de urgência. Dentre estes, 7 possuíam a urgência requerida pelo Presidente da República a projetos de sua iniciativa, nos termos do preceito constitucional do art. $64, \S 1^{\circ}, \mathrm{CF}$, tendo os 81 restantes sofrido pedidos de urgência para apreciação imediata, em conformidade com o art. 155, RICD.

Cabe ressaltar, ainda, que das 88 proposições urgentes aprovadas pelo Plenário, 41 (47\%) já pertenciam à competência do Plenário e 47 (53\%) eram, inicialmente, sujeitas ao procedimento legislativo descentralizado. Ao receber o pedido de urgência, esses projetos também passaram a ser submetidos à deliberação pelo Plenário, perdendo as comissões, assim, seu poder de sobre eles decidir.

\subsection{Análise e conclusões}

A primeira constatação feita com o exame dos dados levantados refere-se à enorme quantidade de projetos de lei recebidos pela Casa durante o período pesquisado - quantidade 
essa que tem, inclusive, aumentado no decorrer das legislaturas ${ }^{1}-\mathrm{e}$, em especial, daqueles cuja tramitação é sujeita à apreciação conclusiva das comissões, visto representarem eles a grande maioria - 5.529 - dos 7.709 apresentados (cerca de $72 \%$ do total). O fato de que apenas uma parcela dessas proposições obteve algum tipo de deliberação dentro da legislatura e de que 3.814 foram arquivadas em decorrência do término da legislatura demonstra a incapacidade do procedimento descentralizado de deliberar sobre todos os projetos que a ele são submetidos.

Entretanto, apesar de o poder conclusivo ter apresentado limitações em responder à demanda, a sua capacidade deliberativa, que se deu em quase $20 \%$ dos casos, revelou-se bastante alta se considerados os números absolutos, uma vez que, em apenas quatro anos, 1.093 projetos de lei foram deliberados, somados os aprovados, os rejeitados, os inadmitidos e os declarados prejudicados.

Em relação a todos os projetos de lei aprovados na Câmara dos Deputados, os dados apurados demonstram, em contraposição ao panorama deixado pelas pesquisas realizadas nas primeiras legislaturas após 1988, uma evolução do poder conclusivo, o que é comprovado pelo fato de que, do total de 286 proposições aprovadas, cerca de 66\% (189) foram resultantes desse tipo de apreciação. Quando comparado o número de proposições que se transformaram em lei (160), apesar de o procedimento de Plenário (91) ter superado o descentralizado (69), a produção legislativa deste foi bastante considerável, na ordem de 43\%. Quanto às 126 proposições que aguardavam a deliberação do Senado Federal, os projetos sujeitos ao poder conclusivo representaram a larga maioria de $95 \%$ desse universo, consistindo os de Plenário em apenas $5 \%$. Todos esses números revelam que as comissões desempenharam com destaque sua função legislativa no uso da competência plena.

No que se refere à atribuição do regime de urgência para a tramitação de projetos de lei inicialmente submetidos ao procedimento descentralizado - identificada pela quase totalidade dos trabalhos anteriores como o principal fator de enfraquecimento do poder decisório das comissões, por enviar as proposições à competência do Plenário -, sua influência não se mostrou tão determinante na legislatura em exame, uma vez que as comissões, apesar de terem perdido a competência plena em 47 das 88 proposições urgentes convertidas em lei, mesmo assim produziram, por meio de sua deliberação definitiva, a quantidade expressiva de 69 leis. Considerando, ainda, que das 91 leis aprovadas em Plenário, apenas 5\% (3) não tramitaram em regime de urgência, pode-se concluir que não fosse o poder conclusivo conferido às comissões, boa parte dos projetos de lei aprovados na Câmara dos Deputados no período pesquisado não teriam sido apreciados.

1 Vieira (2005, p. 83) já havia apurado um número total de 6.923 projetos apresentados na $50^{\mathrm{a}}$ legislatura, e de 7080, na 51 ${ }^{\mathrm{a}}$ legislatura. Em comparação com essas, a $52^{\mathrm{a}}$ Legislatura mostra um número ainda maior da apresentação de projetos de lei, que, como se viu, totalizaram 7.709. 
No que diz respeito à iniciativa das leis aprovadas, os resultados confirmaram aquilo que já havia sido objeto de estudo específico em Pacheco (2004): no rito do poder conclusivo, a iniciativa parlamentar é largamente prevalecente, havendo sido aprovadas 47 leis originárias de projetos de autoria de Deputado ou Senador contra apenas 19 do Executivo, relação que se inverte completamente quando se tomam em consideração as leis aprovadas pelo procedimento tradicional de Plenário, no qual a iniciativa do Executivo supera de longe todas as demais. Percebe-se, com isso, que o Plenário prioriza, em sua apreciação, as proposições do Executivo em detrimento das de seus próprios membros.

Finalmente, a análise dos dados também revelou que o poder de decisão das comissões funciona como um sistema de triagem, tendo posto fim à tramitação de um bom número de projetos de lei que não estavam aptos a entrar para o mundo jurídico, seja por problemas de constitucionalidade e juridicidade ou de adequação financeira ou orçamentária, seja por questões de mérito. No período investigado pelo presente estudo, o procedimento descentralizado foi responsável pelo encerramento da tramitação de 680 proposições, por rejeição e por parecer terminativo das Comissões de Constituição e Justiça e de Cidadania e de Finanças e Tributação.

\section{Considerações Finais}

Este trabalho demonstrou que as comissões da Câmara dos Deputados têm se mostrado como um grande canal de deliberação legislativa, cumprindo cada vez mais ativamente seu papel como centro de poder decisório.

Como se afirmou no início deste artigo, o que motivou nossa pesquisa foram as mudanças assinaladas pelo Anuário Estatístico de 2005 em contraposição aos dados revelados por pesquisas de períodos anteriores. A intenção foi averiguar se elas constituiriam um fato isolado daquele ano em exame ou se traduziriam um ânimo de permanência rumo à efetividade do instituto.

Do exame dos trabalhos das comissões parlamentares, no âmbito de seu poder decisório, durante a $52^{\mathrm{a}}$ Legislatura, pôde-se perceber que houve uma verdadeira evolução desse procedimento, uma vez que seus resultados foram bastante representativos quanto ao total das deliberações, seja pela aprovação, seja pela rejeição de projetos de lei.

O procedimento descentralizado das comissões vem se constituindo em uma via deliberativa da qual a Casa não pode mais prescindir, haja vista ser ele cada vez mais incumbido da apreciação da esmagadora maioria de projetos de lei que ali tramitam. Além disso, o número crescente de proposições apresentadas à Câmara dos Deputados deixa claro que seria impossível ao Plenário exercer tal função sozinho, sem o auxílio das comissões.

Não se deve, no entanto, julgar a eficácia desse instituto com base em números isolados e desvinculados da realidade em que se inserem. O relevante papel das comissões no 
desempenho das funções do Poder Legislativo consiste no debate técnico mais apurado das matérias e na maior interação com a sociedade, do que resultam melhores condições de tomada de decisão sobre os projetos sujeitos à sua apreciação definitiva.

Portanto, é necessário que o poder conclusivo das comissões tenha maior visibilidade perante a sociedade, por meio da divulgação dos trabalhos desenvolvidos e dos resultados alcançados. É importante, também, que ele seja mais valorizado pela própria Câmara dos Deputados e subsidiado de recursos humanos e materiais que dêem maior vazão à grande demanda de proposições e viabilizem deliberações com maior qualidade.

\section{Referências}

Anuário estatístico do processo legislativo. - Ano 1 (2005) - Brasília: Câmara dos Deputados, Coordenação de Publicações, 2006.

BRASIL. Constituição (1988). Constituição da República Federativa do Brasil: texto consolidado até a emenda constituicional n. 43. Brasília: Senado Federal, Subsecretaria de Edições Técnicas, 2004.

BRASIL. Congresso. Câmara dos Deputados. Regimento interno da Câmara dos Deputados. 7. ed. Brasília: Câmara dos Deputados, Coordenação de Publicações, 2006.

CINTRA, Antônio Octávio e LACOMBE, Marcelo Barroso. A Câmara dos Deputados na Nova República: a visão da Ciência Política. Em: AVELAR, Lúcia e CINTRA, Antônio Octávio (org.), Sistema Político Brasileiro: uma introdução. Rio de Janeiro: Fundação KonradAdenauer-Stiftung; São Paulo: Unesp, 2004.

PACHECO, Luciana Botelho. O poder conclusivo de apreciação das comissões da Câmara dos Deputados: uma alternativa viável para a apreciação dos projetos de lei de iniciativa parlamentar. Monografia de conclusão do Curso de Especialização em Assessoria Parlamentar e Processo Legislativo. 2004.

SEGADO, Francisco Fernandez. El procedimiento legislativo descentralizado em Itália y Espana. Em: Estudos de direito constitucional em homenagem a José Afonso da Silva. São Paulo: Malheiros, 2003.

VIEIRA, Fernando Sabóia.. O poder de apreciação conclusiva das comissões da Câmara dos Deputados - uma avaliação. Monografia de conclusão do Curso de Especialização em Gestão Legislativa. 2005. 